\title{
Fatal interstitial pneumonia caused by bovine coronavirus in cows from
}

\section{Southern Italy}

\author{
Maria Grazia Amoroso ${ }^{1 * \pm}$, Giuseppe Lucifora ${ }^{2 \pm}$, Barbara degli Uberti ${ }^{1}$, Francesco Serra ${ }^{1}$, \\ Alessandro Di Domenico ${ }^{3}$, Maria Concetta Cuomo ${ }^{1}$, Giovanna De Luca ${ }^{1}$ Francesca Bove $^{1}$, \\ Giorgio Galiero', Giovanna Fusco' ${ }^{1}$ \\ ${ }^{1}$ Unit of Virology, Department of Animal Health, Experimental Zooprophylactic Institute of \\ Southern Italy, Via Salute, 2, 80055, Portici (NA), Italy \\ ${ }^{2}$ Section of Vibo Valentia, Experimental Zooprophylactic Institute of Southern Italy, C/da \\ Piano di Bruno 89852 Mileto (VV) \\ ${ }^{3}$ Freelance veterinary \\ *Author for correspondence. E-mail: mamoroso@izsmportici.it; \\ ${ }^{ \pm}$The two authors equally contributed to the paper
}

Keywords: Bovine coronavirus, intersititial pneumonia, phylogenetic analysis, Real time PCR

\begin{abstract}
An outbreak of winter disease, complicated by severe respiratory syndrome, occurred in January 2020 in a high production dairy cow herd located in a hilly area of the Calabria region. Of the 52 animals belonging to the farm, 5 (9.6\%) died with severe respiratory distress, death occurring 3-4 days after the appearance of the respiratory signs (caught and gasping breath). Microbiological analysis revealed absence of pathogenic bacteria whilst Real-time PCR identified the presence of RNA from Bovine Coronavirus (BCoV) in several organs: lungs, small intestine (jejunum), mediastinal lymph nodes, liver and placenta. Since being the only pathogen identified, BCoV was hypothesized to be the cause of the lethal pulmonary infection. Like the other CoVs, $\mathrm{BCoV}$ is able to cause different syndromes. Its role in calfhood diarrhoea and in mild respiratory disease is well known: we report instead the involvement of this virus in a severe and fatal respiratory disorder, with symptoms and disease evolution resembling that of Severe Acute Respiratory Syndromes (SARS).
\end{abstract}




\section{Introduction}

Coronaviruses (CoVs) are enveloped viruses, with a RNA single-stranded large genome of 27.6-31 $\mathrm{kb}$ [1]. This big group of viruses, belonging to the order Nidovirales, suborder Coronavirinae, family Coronaviridae, subfamily Orthocornavirinae, is divided, (on the basis of the antigenic and genetic properties of these viruses, [1,2] into 4 genera: alpha, beta, gamma and deltacoronavirus. Coronaviruses are responsible for enteric, respiratory and neurological diseases in both birds and mammals, including humans [3]. Bats and birds are major reservoir of CoVs and some CoVs are endemic in domestic animals in different countries [4]. Several coronaviruses are well known for their ability to change tissue tropism, to pass species barriers and to adapt to new ecological niches. These abilities are related to two factors commonly occurring during RNA replication: accumulation of point mutations (one mutation for each round of replication) caused by the low fidelity of their RNA dependent RNA polymerase (RdRp), as well as homologous and heterologous recombination events [1,2]. These features promote the emergence of novel strains with novel biological properties in term of host range, tissue tropism and virulence [1,5]. The high mutation and recombination rates are indeed implicated in the emergence of new human coronaviruses, of animal origin, like occurred for appearance of the strains HCoV-229E and HCoV-OC43 (the only two human coronaviruses known before SARS emergence, as well as for the arising of SARS-CoV Middle East Respiratory Syndrome Coronavirus Infection, (MERS-CoV) and the recent global pandemic SARS-CoV-2 [1,3,6-8]. CoVs infections in veterinary medicine are well known from a long time [1]. The most common animal CoVs are: infectious bronchitis virus (chickens), porcine transmissible gastroenteritis, porcine hemagglutinating encephalomyelitis and porcine epidemic diarrhoea CoVs (swine), bovine coronavirus (BCoV, cattle), canine enteric and canine respiratory CoVs (dogs), and feline coronavirus (cats) [3]. BCoV belongs, together with human coronavirus (OC43), human enteric coronavirus (4408) and canine respiratory coronavirus (CRCoV), to subgroup A of the betacoronavirus genera [9-11]. This virus is pneumoenteric and has a dual tissue tropism, infecting both intestine and respiratory apparatus (upper and lower tracts), a feature in 
common with human SARS and SARS-CoV-2 [5]. It is endemic in all the world and is considered one of the major causes of neonatal calf diarrhoea, with mortality related to virus ability to destroy the intestinal villi and to cause severe bloody diarrhoea [2]. In adult dairy cattle, BCoV is instead responsible for the well known winter dysentery (WD), which is associated with severe drop in milk production and consequent significant economic losses for the herds [2]. In cattle of various ages the virus is also responsible for respiratory infections (bovine respiratory disease complex, shipping fever of feedlot cattle [5]. In our study we report an outbreak of possible WD in a calf breeding of Southern Italy. The majority of animals showed gastrointestinal disease with bloody diarrhoea and mild respiratory symptomatology (cough, slight temperature increase, nasal discharge). Among them, 5 displayed a very severe respiratory illness, which evolved with animals death within very few days after the occurrence of the first respiratory difficulties. To ascertain the cause of death, animals underwent necroscopy and organs were analysed for the presence of possible bacterial and viral pathogens respectively with cultural and molecular methods.

\section{Materials and Methods}

\subsection{Outbreak description}

The herd consisted of a total population of 52 Italian Friesian cows. The cattle were housed under a single canopy and separated into production groups with feeders on the central corridor and drinking bowls inside each paddock. The production system was characterized by internal recovery. No movements or purchases occurred in the last three years. At the beginning of January 2020 most of the cows, all vaccinated against bovine alphaherpesvirus 1 (BoHV-1) and bovine viral diarrhoea virus (BVD), began to experience symptoms related to winter disease. In the following days about $90 \%$ of the cows showed bloody diarrhoea and a decrease in milk production of up to two thirds. Dry cows and juveniles showed no symptoms. After about 5 days, the majority of cows with diarrhoea began to have respiratory symptoms, with cough and catarrhal secretion, dyspnoea and moderate febrile rise. In some of them, the symptoms worsened with manifestation of pneumoderm 
and pneumothorax. In particular two lactating cows (of about 4 years old) in the fourth month of pregnancy started to show mild respiratory symptoms which aggravated becoming very serious in 1-2 days. The two bovines died in 3-4 days after the appearance of the first respiratory difficulties. Later on, 3 more animals, (of about 7 years old), died after showing the same symptomatology. About ten days later, respiratory and gastrointestinal symptoms of the other animals started to regress. Died animals underwent necropsy to investigated the cause of death and organs together with faecal material were analysed for the presence of bacterial, viral and parasite pathogens.

\subsection{Histopathological analysis}

Tissues of the organs were fixed in $10 \%$ neutral phosphate-buffered formalin and processed by routinary methods into paraffin blocks which were cut into 3-4 $\mu \mathrm{m}$ thick sections and stained with hematoxylin and eosin.

\subsection{Bacteriological and parasitological analysis}

Lungs, liver, kidneys, spleen, meseraic and supramammary lymphnodes as well as cephalorachid fluid were tested by bacterial culture methods to determine the possible cause of death. Briefly, samples were inoculated on both MacConkey agar no. 3 (CM0115 Oxoid) plates and blood agar (7\% v/v ovine blood in blood agar base, CM0271 Oxoid) plates. MacConkey agar plates were incubated at $37^{\circ} \mathrm{C}$ for $48 \mathrm{~h}$, while blood agar plates were incubated at $37^{\circ} \mathrm{C}$ for up to $72 \mathrm{~h}$ in presence/absence of $5 \% \mathrm{CO}_{2}$ Mycoplasma spp. was investigated in lungs and kidneys by inoculating samples in culture broth and plates following protocols usually employed in our laboratories. Faecal material of the animals during the disease was analysed for the presence of helminth eggs and coccidia oocysts with routinary methods. 


\subsection{Viral Nucleic acids extraction procedures}

Each organ ( $25 \mathrm{mg}$ of tissue in $1 \mathrm{ml}$ Phosfate buffered saline solution) was homogenated by Tissue Lyser (Qiagen). Nucleic acid extraction was carried out from $200 \mu$ l of organ homogenate by using Qiasimphony automated extraction system (Qiagen) with the DSP Virus/Pathogen Mini kit (Qiagen) according to the manufacturer's instructions. Nucleic acids were eluted in $60 \mu$ l of elution buffer containing 40 unit/ $\mu$ l RNase inhibitor (Promega) and immediately analysed by Real-time PCR.

\subsection{Real Time virus identification}

DNA viruses like bovine alphaherpesvirus 1 (BoHV-1), bovine alphaherpesvirus 2 (BoHV2), bovine alphaherpesvirus 4 (BoHV4) were investigated by Real-time polymerase chain reaction using Quantitect Real time PCR detection kit (Qiagen). RNA viruses: bovine coronavirus, (BCoV), bovine viral diarrhoea virus (BVDV), border disease virus (BDV), parainfluenza virus 3 (PI3) and respiratory syncytial virus (RSV) were analysed by Real-time reverse transcription polymerase chain reaction using AGPATH reaction kit (Thermo Fisher Scientific). All the reactions were carried with primers (TemaRicerca) and probes (Thermo Fisher Scientific) specific for the virus tested on a Quantstudio5 system (Thermofisher) with protocols routinely used in our laboratory. In particular $\mathrm{BCoV}$ was identified following literature [12] with $\mathrm{BCoV}$ positive control was kindly given by Friederich institute, Germany.

\subsection{BCoV sequencing}

In order to characterize the strains of $\mathrm{BCoV}$ identified, $5 \mathrm{ul}$ of nucleic acids underwent RT-PCR to amplify a 456 bp fragment of the RNA-dependent RNA polymerase (rdrp) gene [13]. The reaction was carried out with AGPATH reaction kit (Thermo Fisher Scientific), using $1.25 \mu$ l of each primer $(10 \mu \mathrm{M})$ with the following thermal profile: $50^{\circ} \mathrm{C}$ for 30 minutes, $95^{\circ} \mathrm{C}$ for $15 \mathrm{~min}, 45$ cycles of $94^{\circ} \mathrm{C}$ for $30 \mathrm{sec}, 50^{\circ} \mathrm{C}$ for $30 \mathrm{sec}, 68^{\circ} \mathrm{C}$ for $30 \mathrm{sec}$ and a final elongation step of $72^{\circ} \mathrm{C}$ for 10 
minutes. PCR products were analysed by Tape station (Agilent) using the D 1000 kit. Amplicons were sequenced by capillary electrophoresis as previously described [14]. The nucleotide sequence similarity searches were performed using the BLAST server (http://www.ncbi.nlm.nih.gov/genbank/index.html) and phylogenetic analysis was carried out using the Jalview and MEGA 7 softwares.

\section{Results}

\subsection{Necroscopical findings}

Of the 52 cows present in the breeding, 5 (9.6\%) died with severe respiratory distress, death occurring 3-4 days after the appearance of the respiratory signs (caught and gasping breath). Anatomo-pathological inspection of the dead cows showed similar frames herein described. We first of all observed congested explorable mucous membranes and haemorrhagic lymphadenitis of the supra-mammary glands. Jejunum was affected by hemorrhagic enteritis with the rectal ampoule containing little hemorrhagic diarrhoea. There was catarrhal lymphadenitis of the meseraics. Liver showed increased volume and was characterised by sub-glissonian haemorrhages and diffuse centro-lobular necrosis. Moderate splenomegaly with sub capsular extravasations at the visceral surface was observed. Kidneys showed red infarcts involving cortical and medullar tissues (Figure 1A). Foetus of around 4 months old was characterized by diffuse subcutaneous haemorrhages. With respect to thoracic cavity we observed diffuse fibrinous-hemorrhagic pleurisy; thymus was studded with hemorrhagic petechiae. Respiratory apparatus showed severe imposing tracheo-bronchitis and muco-hemorrhagic bronchiolitis with the deposition of fibrin molds. Lungs (Figure 1B) were characterized by diffuse fibrinous pleurisy, emphysematous interstitial pneumonia and hemorrhagic mediastinal lymphadenitis. The heart, in diastole, revealed petechial haemorrhages of the epicardium along the coronary and ventricular endocardium, thinning of the right ventricular wall and thickening of the left, with heart basis showing fibrinous epicarditis. 

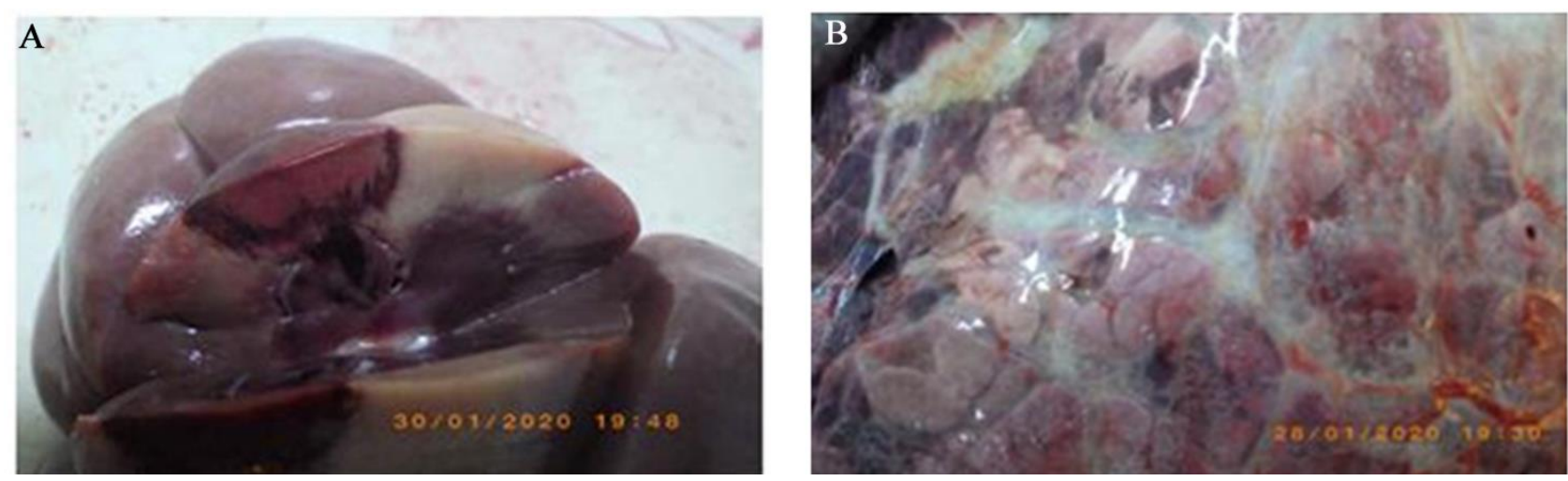

Figure 1. (A) Kidney showing infarcts involving cortical and medullary tissue. (B) Lung with diffuse fibrinous pleurisy and emphysematous interstitial pneumonia.

\subsection{Histopathology}

Microscopic examination of the lungs (Figure 2A, 2B) demonstrated pleural thickening and fibrin mixed with extra-pleural exudates. There were observed areas of subpleural emphysema and alveolar rupture with accumulation of dense eosinophilic material as well as multifocal inflammatory thickening of the pulmonary interstitium with a clear prevalence of foamy macrophages, lymphocytes and plasma cells. Lympho-plasmacellular vasculitis and thrombosis were also described. The bronchial and bronchiolar lumen showed accumulation of dense material and cellular debris mixed with macrophages and lymphocytes. Moderate hyperplasia of the bronchiole-associated lymphoid tissue (BALT) was visible. 

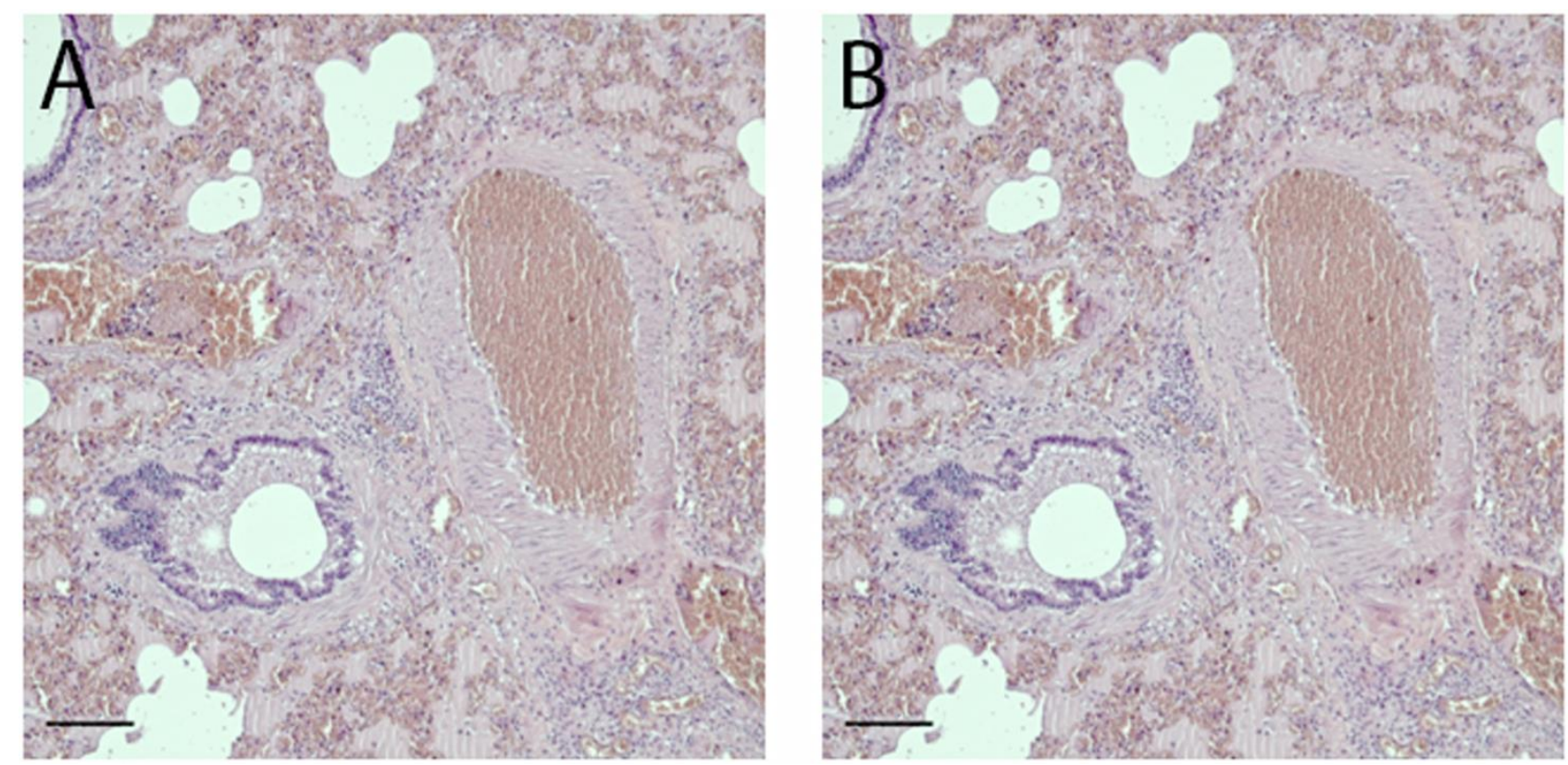

Figure 2. Histopathological observation of the lungs (10x magnification field). (A): vascular thrombosis, lympho-plasmacellular vasculitis and oedema. (B): interstitial pneumonia, oedema, fibrosis.

Sporadic multinucleated cell syncytes in the peri-bronchial site were identified. Ischemic necrosis of a thrombotic nature from vasculitis, characterized by the presence of fibrin, lymphocytes, plasma cells and rare granulocytes, was found in the liver, spleen, kidney (Fig. 3A), thymus (Fig. 3B) and skin of the foetus. Fasting presented tissue disruption and morpho-structural alteration of the villi. Complete de-epithelialisation and accumulation of cellular debris and red blood cells was observed in the lumen. Lymphocytes and granulocytes with a clear prevalence of eosinophils were mainly represented to mediate the inflammatory process. 

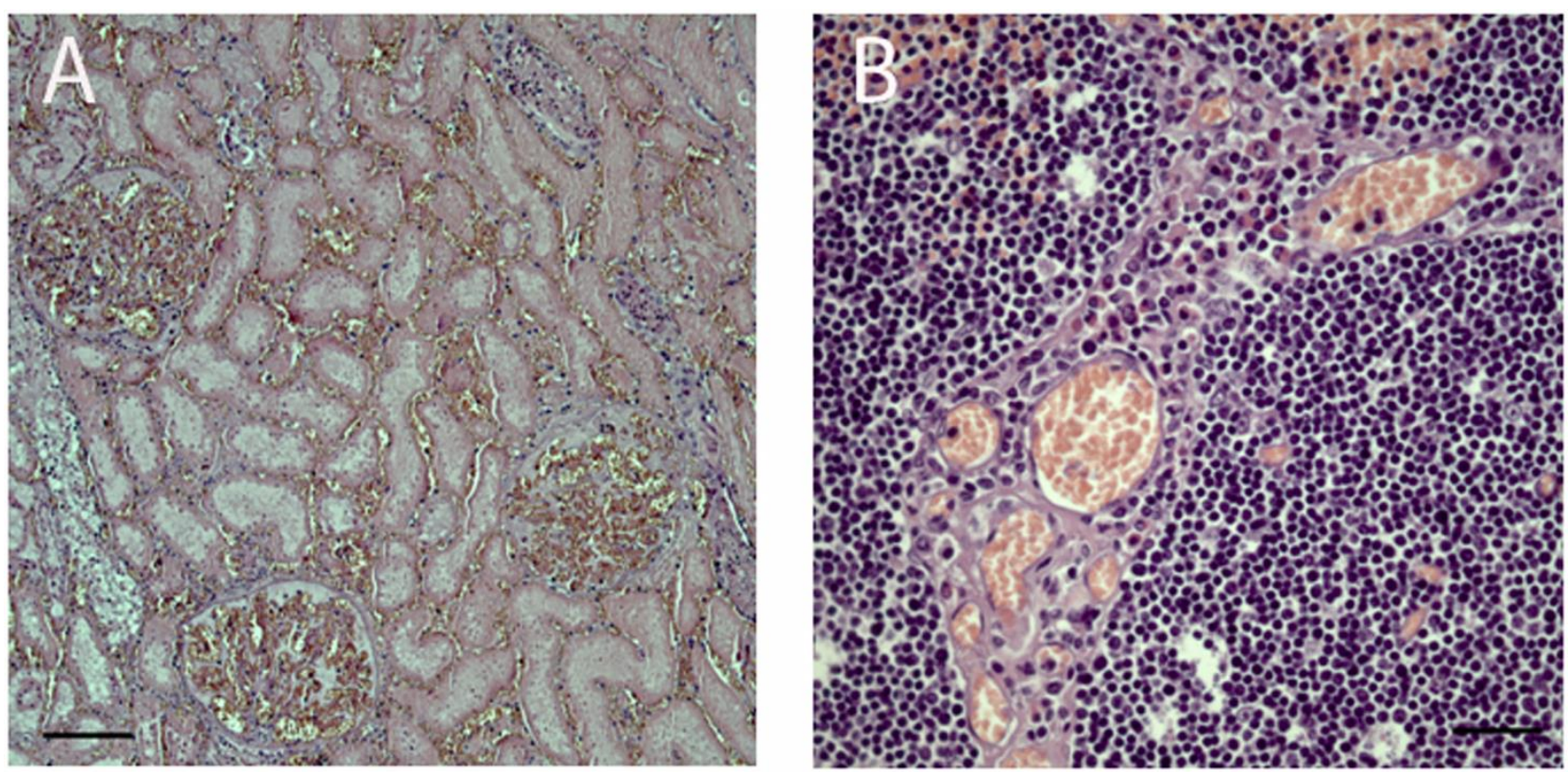

Figure 3. Histopathological observation of (A): kidney (10x magnification field) with glomerular thrombosis, tubular ischemic necrosis and interstitial congestion; (B) thymus (40x magnification field) characterized by vasculitis and ischemic necrosis.

\subsection{Microbiology and virology}

Microbiological analysis revealed absence of pathogenic bacteria in all the organs. No parasites were recognized in the faecal material. Virological investigations gave instead interesting results. Real time PCR carried out on the organs of the animals gave negative results for all the herpesviruses investigated as well for: BVDV, BDV and PI3. The only pathogen identified was $\mathrm{BCoV}$, that was detected in: lungs, small intestine (jejunum), mediastinal lymph nodes, liver and placenta. Foetal thymus, kidney and spleen resulted instead negative for the virus. Among the positive organs, lungs showed a very high signal of fluorescence (threshold cycle, $C_{t}=20$ ) with respect to other samples with displayed a $C_{t}$ ranging from 25 to 32.

\subsection{Sequencing analysis of $B C o V$}

As shown in Figure 4, sequencing and phylogenetic analysis of the $\mathrm{BCoV}$ identified (partial Rdrp gene, Genbank accession number, AC: MT602514) revealed the highest homology (99\%), with a 
strain isolated from a bovine in France in 2013 (AC: KT318104), with only one base substitution (c instead of a). Among the bovine coronaviruses, our strain was also closely related (two nucleotides of difference) to a $\mathrm{BCoV}$ identified in India in 2015, and to two $\mathrm{BCoVs}$ (one respiratory and one enteric) isolated in USA respectively in 1996 and 2002. Among the non-bovine CoVs, the highest homology was shown with a bovine-like CoV isolated from an alpaca in USA in 2007 and with a human enteric coronavirus 4408 (FJ415324) collected in 1988 from a patient in Germany.

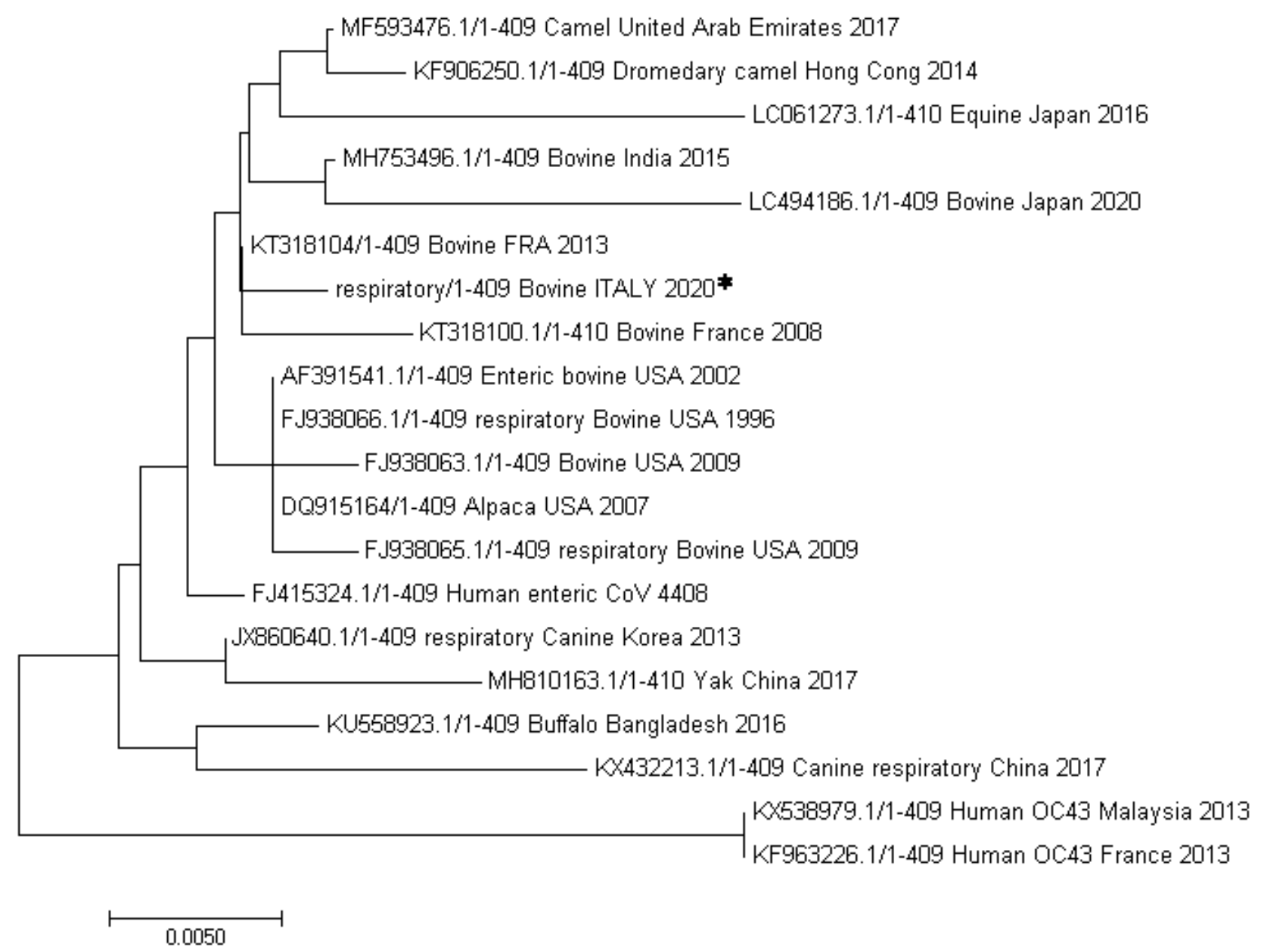

Figure 4. Phylogenetic analysis of a part of the rdrp gene (409 bp). The evolutionary history was inferred using the Neighbor-Joining method [15]. The optimal tree with the sum of branch length = 0.10294269 is shown. The evolutionary distances were computed using the Poisson correction method and are in the units of the number of amino acid substitutions per site. Evolutionary analyses were conducted in MEGA7 [16]. Sequence obtained in the present study (Bovine ITALY 2020) is indicated with an asterisk. 


\section{Discussion}

In our study we described a strong pulmonary infection, likely provoked by bovine coronavirus, which lead to the death of 5 animals in a high genealogy Friesian dairy cows breeding. The infection involved $90 \%$ of the animals with gastrointestinal and mild respiratory symptoms but for few animals the pathogen showed to be more aggressive leading to a dead prevalence of $5.2 \%$. Since BCoV was the only pathogen identified, its role in the fatal pneumonia appeared unequivocal. As a matter of fact while the involvement of $\mathrm{BCoV}$ in enteric infections is well known, its role in bovine respiratory disease is controversial and principally related to mild respiratory symptomatology. The virus has been indeed found in respiratory samples from both healthy and sick cattle [11,17-21] and more frequently identified in association with other respiratory pathogens $[11,18,22-24]$. Only few papers reported instead $\mathrm{BCoV}$ as the only recognized cause of the disease $[9,22,25]$. Furthermore, there are various studies in literature describing attempts to provoke clinical respiratory symptoms by infecting healthy cattle with $\mathrm{BCoV}$ inocula. Results showed in most experiments no symptomatology in some cases the developing of gastrointestinal disease [26-29], with only few reports describing slight respiratory problems [30,31]. Our results seem to corroborate the role of this virus in respiratory outbreaks and to point out the ability of the virus to provoke, in the same animal or within the same outbreak, both enteric and respiratory symptoms, confirming what already reported by Choulienko et al. [32]. With respect to the 5 fatal pneumonia cases, the observed exacerbation of the respiratory disease in these animals, resembling what happens for other severe coronavirus syndromes (like those caused by SARS, MERS, COVID-19), could have been related to various co-factors including: immunosuppression (due to corticosteroids treatment), individual host susceptibility, co-morbilities, physical stresses [5]. What's more, since through recombination events $\mathrm{CoVs}$ are able to gain novel biological properties, including an increased pathogenicity (Decaro et al. 2020), we could also fascinatingly hypothesize the identification of a more pathogenic variant of bovine coronavirus, with acquired ability to cause 
fatal pneumonia in susceptible hosts. Further studies including isolation of the virus and full genome sequencing oould be necessary to confirm this hypothesis.

In the last 17 years, starting from the SARS-CoV epidemics in 2003 and till the current COVID-19 pandemic, CoVs have been greatly highlighted because of their capability to adapt new tissues tropisms and to jump host-species barriers $[1,2,32]$. In less than twenty years we assisted to the emergence of three highly pathogenic CoVs all of zoonotic origin. These viruses with reservoirs in bats and rodents, have passed the species barriers jumping to humans through intermediate animals [1]. BCoV shares with the human highly pathogen CoVs (SARS, MERS and SARS-CoV-2) ,the feature to have a broad host range and to be competent of infecting multiple species thus showing a likely zoonotic potential $[3,5,34]$. As a matter of fact, many bovine-like CoVs has been indeed identified as enteric and/or respiratory pathogens in both livestock and wildlife species (wild ruminants, captive ruminants as well as water buffalo, camelids, [5,10,35-39]. With respect to the possibility of BCoV-like viruses to infect humans, in literature it has been described a case of child acute enteritis caused by a human $\mathrm{CoV}$ found genetically and antigenetically more closely related to BCoV than to HCoV-OC43 [40]. What's more HCoV-OC43 has been supposed to derive from an ancestral $\mathrm{BCoV}$ strain (considering their close genetic and antigenic similarity) which jumped the species barrier and had passed from rodents to humans through cattle [41-43]. Interestingly, phylogenetic analysis showed that our strain, with respect to the part of rdrp gene analysed, was very closely related to an enteric $\mathrm{HCoV}-4408$ described in a patient in Germany (see Figure 4). Interspecies transmission via wildlife and livestock host animals are key factors for the emerging of new, highly pathogenic, human coronaviruses. For this reason it is of utmost important to focus on and carefully investigate the outbreaks in which animal coronaviruses are involved, with particular regard to clinical symptomatology and genetic classification. What's more, in the case of BCoVs, it is necessary to recommend the farmers to strictly follow all the protection and prevention biosafety measures necessary to limit the diffusion of such viruses among animals and to avoid any possible 
human contamination, since also viruses like $\mathrm{BCoV}$ always regarded as "only" of zootecnic interest, could become very dangerous for the collective health.

\section{Conflict of interest statement}

The authors declare that they have no conflicts ofinterest.

\section{Funding}

This research did not receive any specific grant from funding agencies in the public, commercial, or not-for-profit sectors.

Author contributions: Conceptualization, Maria Grazia Amoroso, Giuseppe Lucifora, Alessandro Di Domenico, Giorgio Galiero and Giovanna Fusco; Data curation, Giuseppe Lucifora; Formal analysis, Giuseppe Lucifora, Barbara Degli Uberti, Francesco Serra, Alessandro Di Domenico, Maria Concetta Cuomo, Giovanna De Luca and Francesca Bove; Funding acquisition, Giovanna Fusco; Investigation, Maria Grazia Amoroso and Giovanna Fusco; Methodology, Maria Grazia Amoroso; Supervision, Maria Grazia Amoroso, Giuseppe Lucifora, Giorgio Galiero and Giovanna Fusco; Writing - original draft, Maria Grazia Amoroso, Giuseppe Lucifora, Barbara Degli Uberti and Giorgio Galiero

\section{REFERENCES}

1. Decaro, N.; Lorusso, A. Novel Human Coronavirus (SARS-CoV-2): A Lesson from Animal Coronaviruses. Vet. Microbiol. 2020, 244, 108693.

2. Amer, H.M. Bovine-Like Coronaviruses in Domestic and Wild Ruminants. Anim. Health. Res. Rev. 2018, 19, 113-124.

3. Abdel-Moneim, A.S.; Abdelwhab, E.M. Evidence for SARS-CoV-2 Infection of Animal Hosts. Pathogens 2020, 9, 10.3390/pathogens9070529.

4. Saif, L.J. Animal Coronaviruses: What can they Teach Us about the Severe Acute Respiratory Syndrome?. Rev. Sci. Tech. 2004, 23, 643-660.

5. Saif, L.J.; Jung, K. Comparative Pathogenesis of Bovine and Porcine Respiratory Coronaviruses in the Animal Host Species and SARS-CoV-2 in Humans. J. Clin. Microbiol. 2020, 58, 10.1128/JCM.01355-20. Print 2020 Jul 23.

6. Stavrinides, J.; Guttman, D.S. Mosaic Evolution of the Severe Acute Respiratory Syndrome Coronavirus. J. Virol. 2004, 78, 76-82.

7. Hon, C.C.; Lam, T.Y.; Shi, Z.L.; Drummond, A.J.; Yip, C.W.; Zeng, F.; Lam, P.Y.; Leung, F.C. Evidence of the Recombinant Origin of a Bat Severe Acute Respiratory Syndrome (SARS)-Like Coronavirus and its Implications on the Direct Ancestor of SARS Coronavirus. J. Virol. 2008, 82, 1819-1826. 
8. Corman, V.M.; Ithete, N.L.; Richards, L.R.; Schoeman, M.C.; Preiser, W.; Drosten, C.; Drexler, J.F. Rooting the Phylogenetic Tree of Middle East Respiratory Syndrome Coronavirus by Characterization of a Conspecific Virus from an African Bat. J. Virol. 2014, 88, 11297-11303.

9. Decaro, N.; Campolo, M.; Desario, C.; Cirone, F.; D'Abramo, M.; Lorusso, E.; Greco, G.; Mari, V.; Colaianni, M.L.; Elia, G.; et al. Respiratory Disease Associated with Bovine Coronavirus Infection in Cattle Herds in Southern Italy. J. Vet. Diagn. Invest. 2008a, 20, 28-32.

10. Decaro, N.; Martella, V.; Elia, G.; Campolo, M.; Mari, V.; Desario, C.; Lucente, M.S.; Lorusso, A.; Greco, G.; Corrente, M.; et al. Biological and Genetic Analysis of a Bovine-Like Coronavirus Isolated from Water Buffalo (Bubalus Bubalis) Calves. Virology 2008b, 370, 213-222.

11. Ellis, J. What is the Evidence that Bovine Coronavirus is a Biologically Significant Respiratory Pathogen in Cattle?. Can. Vet. J. 2019, 60, 147-152.

12. Decaro, N.; Elia, G.; Campolo, M.; Desario, C.; Mari, V.; Radogna, A.; Colaianni, M.L.; Cirone, F.; Tempesta, M.; Buonavoglia, C. Detection of Bovine Coronavirus using a TaqManBased Real-Time RT-PCR Assay. J. Virol. Methods 2008, 151, 167-171.

13. Drosten, C.; Gunther, S.; Preiser, W.; van der Werf, S.; Brodt, H.R.; Becker, S.; Rabenau, H.; Panning, M.; Kolesnikova, L.; Fouchier, R.A.; et al. Identification of a Novel Coronavirus in Patients with Severe Acute Respiratory Syndrome. N. Engl. J. Med. 2003, 348, 1967-1976.

14. Amoroso, M.G.; Corrado, F.; De Carlo, E.; Lucibelli, M.G.; Martucciello, A.; Guarino, A.; Galiero, G. Bubaline Herpesvirus 1 Associated with Abortion in a Mediterranean Water Buffalo. Res. Vet. Sci. 2013, 94, 813-816.

15. Saitou, N.; Nei, M. The Neighbor-Joining Method: A New Method for Reconstructing Phylogenetic Trees. Mol. Biol. Evol. 1987, 4, 406-425.

16. Kumar, S.; Stecher, G.; Tamura, K. MEGA7: Molecular Evolutionary Genetics Analysis Version 7.0 for Bigger Datasets. Mol. Biol. Evol. 2016, 33, 1870-1874.

17. Hasoksuz, M.; Lathrop, S.L.; Gadfield, K.L.; Saif, L.J. Isolation of Bovine Respiratory Coronaviruses from Feedlot Cattle and Comparison of their Biological and Antigenic Properties with Bovine Enteric Coronaviruses. Am. J. Vet. Res. 1999, 60, 1227-1233.

18. Fulton, R.W.; Blood, K.S.; Panciera, R.J.; Payton, M.E.; Ridpath, J.F.; Confer, A.W.; Saliki, J.T.; Burge, L.T.; Welsh, R.D.; Johnson, B.J.; et al. Lung Pathology and Infectious Agents in Fatal Feedlot Pneumonias and Relationship with Mortality, Disease Onset, and Treatments. J. Vet. Diagn. Invest. 2009, 21, 464-477.

19. Francoz D, Buczinski S, Belanger G, et al. Respiratory Pathogens in Quebec Dairy Calves and their Relationship with Clinical Status, Lung Consolidation, and Average Daily Gain. J Vet Intern Med 2015, 29, 381-387.

20. Mitra, N.; Cernicchiaro, N.; Torres, S.; Li, F.; Hause, B.M. Metagenomic Characterization of the Virome Associated with Bovine Respiratory Disease in Feedlot Cattle Identified Novel Viruses and Suggests an Etiologic Role for Influenza D Virus. J. Gen. Virol. 2016, 97, 1771-1784.

21. Workman, A.M.; Kuehn, L.A.; McDaneld, T.G.; Clawson, M.L.; Chitko-McKown, C.G.; Loy, J.D. Evaluation of the Effect of Serum Antibody Abundance Against Bovine Coronavirus on 
Bovine Coronavirus Shedding and Risk of Respiratory Tract Disease in Beef Calves from Birth through the First Five Weeks in a Feedlot. Am. J. Vet. Res. 2017, 78, 1065-1076.

22. Storz, J.; Purdy, C.W.; Lin, X.; Burrell, M.; Truax, R.E.; Briggs, R.E.; Frank, G.H.; Loan, R.W. Isolation of Respiratory Bovine Coronavirus, Other Cytocidal Viruses, and Pasteurella Spp from Cattle Involved in Two Natural Outbreaks of Shipping Fever. J. Am. Vet. Med. Assoc. 2000, 216, 1599-1604.

23. Cho, K.O.; Hoet, A.E.; Loerch, S.C.; Wittum, T.E.; Saif, L.J. Evaluation of Concurrent Shedding of Bovine Coronavirus Via the Respiratory Tract and Enteric Route in Feedlot Cattle. Am. J. Vet. Res. 2001a, 62, 1436-1441.

24. Fulton, R.W.; d'Offay, J.M.; Landis, C.; Miles, D.G.; Smith, R.A.; Saliki, J.T.; Ridpath, J.F.; Confer, A.W.; Neill, J.D.; Eberle, R.; et al. Detection and Characterization of Viruses as Field and Vaccine Strains in Feedlot Cattle with Bovine Respiratory Disease. Vaccine 2016, 34, 3478-3492.

25. Fulton, R.W.; Step, D.L.; Wahrmund, J.; Burge, L.J.; Payton, M.E.; Cook, B.J.; Burken, D.; Richards, C.J.; Confer, A.W. Bovine Coronavirus (BCV) Infections in Transported Commingled Beef Cattle and Sole-Source Ranch Calves. Can. J. Vet. Res. 2011, 75, 191-199.

26. Reynolds, D.J.; Debney, T.G.; Hall, G.A.; Thomas, L.H.; Parsons, K.R. Studies on the Relationship between Coronaviruses from the Intestinal and Respiratory Tracts of Calves. Arch. Virol. 1985, 85, 71-83.

27. Saif, L.J.; Redman, D.R.; Moorhead, P.D.; Theil, K.W. Experimentally Induced Coronavirus Infections in Calves: Viral Replication in the Respiratory and Intestinal Tracts. Am. J. Vet. Res. 1986, 47, 1426-1432.

28. Cho, K.O.; Hasoksuz, M.; Nielsen, P.R.; Chang, K.O.; Lathrop, S.; Saif, L.J. Cross-Protection Studies between Respiratory and Calf Diarrhea and Winter Dysentery Coronavirus Strains in Calves and RT-PCR and Nested PCR for their Detection. Arch. Virol. 2001b, 146, 2401-2419.

29. Park, S.J.; Kim, G.Y.; Choy, H.E.; Hong, Y.J.; Saif, L.J.; Jeong, J.H.; Park, S.I.; Kim, H.H.; Kim, S.K.; Shin, S.S.; et al. Dual Enteric and Respiratory Tropisms of Winter Dysentery Bovine Coronavirus in Calves. Arch. Virol. 2007, 152, 1885-1900.

30. McNulty, M.S.; Bryson, D.G.; Allan, G.M.; Logan, E.F. Coronavirus Infection of the Bovine Respiratory Tract. Vet. Microbiol. 1984, 9, 425-434.

31. Kapil, S.; Trent, A.M.; Goyal, S.M. Excretion and Persistence of Bovine Coronavirus in Neonatal Calves. Arch. Virol. 1990, 115, 127-132.

32. Chouljenko, V.N.; Lin, X.Q.; Storz, J.; Kousoulas, K.G.; Gorbalenya, A.E. Comparison of Genomic and Predicted Amino Acid Sequences of Respiratory and Enteric Bovine Coronaviruses Isolated from the Same Animal with Fatal Shipping Pneumonia. J. Gen. Virol. 2001, 82, 2927 2933.

33. Decaro, N.; Mari, V.; Elia, G.; Addie, D.D.; Camero, M.; Lucente, M.S.; Martella, V.; Buonavoglia, C. Recombinant Canine Coronaviruses in Dogs, Europe. Emerg. Infect. Dis. 2010, 16, 41-47. 
34. de Wit, E.; van Doremalen, N.; Falzarano, D.; Munster, V.J. SARS and MERS: Recent Insights into Emerging Coronaviruses. Nat. Rev. Microbiol. 2016, 14, 523-534.

35. Tsunemitsu, H.; el-Kanawati, Z.R.; Smith, D.R.; Reed, H.H.; Saif, L.J. Isolation of Coronaviruses Antigenically Indistinguishable from Bovine Coronavirus from Wild Ruminants with Diarrhea. J. Clin. Microbiol. 1995, 33, 3264-3269.

36. Zhong, N.S.; Wong, G.W. Epidemiology of Severe Acute Respiratory Syndrome (SARS): Adults and Children. Paediatr. Respir. Rev. 2004, 5, 270-274.

37. Decaro, N.; Desario, C.; Elia, G.; Mari, V.; Lucente, M.S.; Cordioli, P.; Colaianni, M.L.; Martella, V.; Buonavoglia, C. Serological and Molecular Evidence that Canine Respiratory Coronavirus is Circulating in Italy. Vet. Microbiol. 2007, 121, 225-230.

38. Lorusso, A.; Desario, C.; Mari, V.; Campolo, M.; Lorusso, E.; Elia, G.; Martella, V.; Buonavoglia, C.; Decaro, N. Molecular Characterization of a Canine Respiratory Coronavirus Strain Detected in Italy. Virus Res. 2009, 141, 96-100.

39. Woo, P.C.; Lau, S.K.; Wernery, U.; Wong, E.Y.; Tsang, A.K.; Johnson, B.; Yip, C.C.; Lau, C.C.; Sivakumar, S.; Cai, J.P.; et al. Novel Betacoronavirus in Dromedaries of the Middle East, 2013. Emerg. Infect. Dis. 2014, 20, 560-572.

40. Zhang, X.M.; Herbst, W.; Kousoulas, K.G.; Storz, J. Biological and Genetic Characterization of a Hemagglutinating Coronavirus Isolated from a Diarrhoeic Child. J. Med. Virol. 1994, 44, 152161.

41. Vijgen, L.; Keyaerts, E.; Moes, E.; Thoelen, I.; Wollants, E.; Lemey, P.; Vandamme, A.M.; Van Ranst, M. Complete Genomic Sequence of Human Coronavirus OC43: Molecular Clock Analysis Suggests a Relatively Recent Zoonotic Coronavirus Transmission Event. J. Virol. 2005, 79, 15951604.

42. Vijgen, L.; Keyaerts, E.; Lemey, P.; Maes, P.; Van Reeth, K.; Nauwynck, H.; Pensaert, M.; Van Ranst, M. Evolutionary History of the Closely Related Group 2 Coronaviruses: Porcine Hemagglutinating Encephalomyelitis Virus, Bovine Coronavirus, and Human Coronavirus OC43. J. Virol. 2006, 80, 7270-7274.

43. Forni, D.; Cagliani, R.; Clerici, M.; Sironi, M. Molecular Evolution of Human Coronavirus Genomes. Trends Microbiol. 2017, 25, 35-48. 